\title{
Tác động của đa dạng hóa Hội đồng quản trị và khoảng cách giữa Chủ tịch Hội đồng quản trị - Tổng giám đốc đến rủi ro của các Ngân hàng thương mại
}

\section{Effects of diversification of the Board of Directors and the gap between the Chairman and Chief Executive Officer (CEO) on commercial banks' risks}

\author{
Phạm Hà ${ }^{1 *}$, Nguyễn Thái Phát ${ }^{1}$, Nguyễn Thị Thu Trang ${ }^{1}$ \\ ${ }^{1}$ Trường Đại học Mở Thành phố Hồ Chí Minh, Việt Nam \\ *Tác giả liên hệ, Email: ha.p@ou.edu.vn
}

THÔNG TIN

DOI: $10.46223 /$ HCMCOUJS.

econ.vi.16.2.937.2021

Ngày nhận: 31/08/2020

Ngày nhận lại: 18/09/2020

Duyệt đăng: 20/11/2020

Tù khóa:

sự đa dạng trong HĐQT; khoảng cách giữa Chair-CEO; rủi ro

Keywords:

diversification in Board of

Directors; , Chair-CEO gap; risks

\section{TÓM TÁ̀T}

Nghiên cứu được thực hiện dựa trên số liệu của 26 ngân hàng thương mại của Việt Nam với mục đích tìm hiểu ảnh hưởng về sự đa dạng trong Hội đồng quản trị và khoảng cách giữa Chủ tịch Hội đồng quản trị (Chair) với Tổng giám đốc (CEO) đến rủi ro của các Ngân hàng thương mại trong giai đoạn 2007 - 2017. Kết quả thực nghiệm của nghiên cứu cho thấy khoảng cách giữa Chủ tịch Hội đồng quản trị và Tổng giám đốc (Chair-CEO) cũng như sự đa dạng của Hội đồng quản trị có ảnh hưởng đến rủi ro của các ngân hàng.

ABSTRACT
The study was conducted based on data of 26 commercial
banks in Vietnam to discover the effects of diversification of the
Board of Directors and the gap between the Chairman of the
Board (Chairman) and Chief Executive Officer (CEO) on
commercial banks' risks in the period from 2007 to 2017. The
study's empirical results show the gap between the Chairman of
the Board and the CEO (Chair-CEO gap), and the
diversification of the Board of Directors also affects the banks'
risks.

\section{Giới thiệu}

Vai trò của đội ngũ quản trị ngân hàng được xem là một trong những nguyên nhân chính gây ra cuộc khủng hoảng tài chính khủng hoảng tài chính toàn cầu 2007 - 2009 (Beltratti \& Stulz, 2012; Peni \& Vähämaa, 2012). Ngày càng có nhiều nghiên cứu thể hiện rằng cơ chế quản trị của một tổ chức thông qua hoạt động của Hội Đồng Quản Trị (HĐQT) có vai trò rất quan trọng trong việc giám sát một cách hiệu quả các rủi ro trong hoạt động của các ngân hàng nhằm tăng cường sự ổn định của hệ thống ngân hàng của một quốc gia (Srivastav \& Hagendorff, 2016). Sự đa dạng trong HĐQT sẽ gia tăng việc quản trị doanh nghiệp và thể hiện qua nhiều khía cạnh khác nhau như kỹ năng, kinh nghiệm cũng như các đặc điểm nhân khẩu học của các cá nhân trong HĐQT (Zhou, Kara, \& Molyneux, 2019). Những khía cạnh này có thể tác động tích cực đến hiệu quả hoạt động của HĐQT thông qua việc ra các quyết định tốt hơn bằng cách đưa ra những quan điểm khác nhau (Van der Walt, Ingley, Shergill, \& Townsend, 2006) và bằng cách tăng cường sự độc lập 
trong suy nghĩ của các thành viên trong HĐQT để thực hiện các chức năng tư vấn và giám sát của mình (Adams \& Ferreira, 2007). Bên cạnh đó, một yếu tố khá quan trọng có liên quan đến HĐQT đó là mối liên hệ giữa Chủ tịch HĐQT (Chair) và Tổng Giám đốc (CEO) cũng cho thấy có ảnh hưởng đáng kể đến khả năng giám sát của HĐQT (Goergen, Limbach, \& Scholz, 2015). Khi Chủ tịch HĐQT và Tổng giám đốc cùng một độ tuổi giống nhau sẽ ít xung đột về mặt nhận thức và điều này có thể làm giảm khả năng giám sát của HĐQT. Tuy nhiên có những nghiên cứu như của Talavera, Yin, và Zhang (2018) về mối liên hệ giữa sự đa dạng về tuổi của các thành viên trong HĐQT cũng như ban giám đốc với rủi ro của các ngân hàng ở Trung Quốc lại không tìm thấy mối quan hệ nào. Bên cạnh đó, Zhou và cộng sự (2019) trong một nghiên cứu về khoảng cách giữa Chủ tịch HĐQT và Tổng giám đốc (hay là khoảng cách thế hệ Chair-CEO) với rủi ro ngân hàng đã chứng minh sự khác biệt về mặt tuổi giữa Chair-CEO làm giảm rủi ro của các ngân hàng, chênh lệch tuổi tác có tác dụng rất lớn trong việc làm giảm rủi ro ngân hàng. Không có một sự nhất quán về mặt thực nghiệm khi tìm hiểu về sự đa dạng của HĐQT cũng như khoảng cách Chair-CEO với rủi ro của các ngân hàng tại các nước. Do đó rất cần có một nghiên cứu tìm hiểu ảnh hưởng của sự đa dạng trong HĐQT và mối liên hệ giữa Chair-CEO với rủi ro của các ngân hàng thương mại tại Việt Nam.

\section{Cơ sở lý thuyết}

Alchian và Demsetz (1972) nhấn mạnh rằng để đảm bảo các hoạt động của ngân hàng được điều hành một cách tốt nhất thì ngân hàng phải (i) thiết lập những cơ chế đãi ngộ thích hợp cho các nhà quản lý, và (ii) thiết lập cơ chế giám sát hiệu quả để hạn chế những hành vi không bình thường, tư lợi của $\mathrm{CEO}$ thông qua HĐQT. Sự đa dạng trong HĐQT có một ảnh hưởng rất lớn đến hiệu quả hoạt động của ngân hàng (Faleye \& Krishnan, 2017; García-Meca, García-Sánchez, \& Martínez-Ferrero, 2015; Liang, Xu, \& Jiraporn, 2013). Tuy nhiên không có một sự nhất quán về ảnh hưởng của các yếu tố đại diện cho sự đa dạng trong HĐQT đến hiệu quả hoạt động của các ngân hàng. Các nghiên cứu thực nghiệm cho thấy số lượng thành viên trong HĐQT có thể ảnh hưởng tích cực (García-Meca et al., 2015) hoặc tiêu cực (Liang et al., 2013) thậm chí là không ảnh hưởng đến hiệu quả hoạt động của ngân hàng (Minton, Taillard, \& Williamson, 2014). Ở các khía cạnh khác như tỷ lệ nữ giới, tỷ lệ thành viên độc lập hay tỷ lệ thành viên người nước ngoài trong HĐQT các nghiên cứu cũng không cho thấy một sự đồng thuận về chiều ảnh hưởng của các khía cạnh này lên hiệu quả hoạt động của ngân hàng (Beltratti \& Stulz, 2012; Berger, Klapper, \& TurkAriss, 2017; Fama \& Jensen, 1983; Muller-Kahle \& Lewellyn, 2011).

Forbes và Milliken (1999) lập luận thêm rằng để đảm bảo tính hiệu quả của HĐQT thì các thành viên trong HĐQT nên độc lập về tư duy và nhận thức trong công việc để các quan điểm khác nhau có thể xuất hiện và các quyết định được đưa ra bởi Ban Giám đốc sẽ được các thành viên trong HĐQT xem xét kỹ lưỡng. Tuy nhiên, điều này rất khó xảy ra nếu các thành viên trong HĐQT đặc biệt là Chair và $\mathrm{CEO}$ giống nhau về mặt nhân khẩu học đặc biệt là tuổi tác. Điều này được McPherson, Smith-Lovin, và Cook (2001) chỉ ra là con người thích tương tác và giao tiếp với những cá nhân có các đặc điểm nhân khẩu học gần giống nhau. Lý do vì các cá nhân giống nhau sẽ đảm bảo các phản hồi gần giống nhau, hạn chế sự bất đồng hay xuất hiện các ý kiến khác. Kết quả là sự tương đồng về mặt nhân khẩu học giữa Chair-CEO có thể dẫn dến việc quản trị doanh nghiệp sẽ kém hiệu quả (xem thêm Fracassi \& Tate, 2012; Westphal \& Zajac, 1995). Ngược lại khi Chair-CEO có sự khác biệt về đặc điểm nhân khẩu học đặc biệt là tuổi thì sẽ giúp gia tăng hiệu quả giám sát của HĐQT đảm bảo sự hoạt động ổn định của doanh nghiệp. Cụ thể, sự khác biệt về tuổi của Chair-CEO càng lớn càng làm tăng sự độc lập về nhận thức của Chair và làm nảy sinh mâu thuẫn giữa Chair-CEO. Điều này sẽ dẫn đến sự xem xét kỹ lưỡng và đưa ra những quyết định chính xác của Chair hơn buộc CEO phải cung cấp thêm các thông tin để thuyết phục 
Chair cũng như các thành viên trong HĐQT. Nói cách khác, CEO buộc phải tăng tính minh bạch bằng cách cung cấp các thông tin chi tiết và có giá trị liên quan đến các chính sách hoạt động được đề xuất (Forbes \& Milliken, 1999). Sự khác biệt nhất định về tuổi của Chair-CEO cũng sẽ dẫn đến xung đột về nhận thức giúp gia tăng sự giám sát của Chair cũng như HĐQT với các hoạt động của $\mathrm{CEO}$ và Ban giám đốc.

\section{Giả thuyết và mô hình nghiên cứu}

\subsection{Giả thuyết nghiên cúu}

\subsubsection{Khoảng cách Chair - CEO và rủi ro của ngân hàng}

Sự khác biệt thế hệ giữa Chair-CEO được thể hiện qua khía cạnh tuổi. Tuổi là một yếu tố quan trọng có thể liên tục ảnh hưởng đến thái độ, hành vi đầu tư, ra quyết định và xử lý thông tin của một cá nhân (Serfling, 2014). Mặt khác, khi Chair-CEO cùng một thế hệ sẽ cùng nhau trải qua các sự kiện lịch sử, các vấn đề trong kinh tế xã hội và có mối liên hệ về mặt tinh thần và tư duy gần giống nhau (Harrison, Price, \& Bell, 1998). Sự tương đồng về tuổi của Chai-CEO là một trong những chỉ số quan trọng trong mối quan hệ giữa Chair-CEO. Tuy nhiên sự tương đồng về tuổi có thể có tác động tiêu cực đến hiệu quả hoạt động của ngân hàng do Chair-CEO có mối quan hệ xã hội mạnh, ít xung đột về mặt nhận thức đối với các vấn đề trong hoạt động của ngân hàng. Khi Chair-CEO có sự khác biệt về tuổi sẽ kéo theo sự xung đột nhận thức về các vấn đề trong hoạt động của ngân hàng sẽ nhiều hơn, củng cố khả năng giám sát, tư vấn của HĐQT (Adams \& Ferreira, 2007; Goergen et al., 2015). Từ đây nghiên cứu đưa ra lập luận là khoảng cách ChairCEO càng lớn thì sẽ làm tăng xung đột nhận thức giữa Chair-CEO dẫn đến việc giám sát cũng như kiểm soát tốt hơn của HĐQT với rủi ro của ngân hàng. Giả thuyết được đề xuất như sau:

$H_{1}$ : Sự khác biệt về tuổi của Chair-CEO có mối quan hệ cùng chiều với rủi ro hoạt động của ngân hàng

Đồng thời nghiên cứu cũng quan tâm đến sự khác biệt về mặt tuổi của Chair-CEO ở một khía cạnh khác đó là khi Chair-CEO ở hai thế hệ khác nhau thì mối quan hệ giữa Chair-CEO sẽ không cao dẫn đến xung đột về mặt nhận thức về các vấn đề trong hoạt động của ngân hàng. Do đó, nghiên cứu đề xuất giả thuyết tiếp theo như sau:

$H_{2}$ : Sự khác biệt về thế hệ Chair-CEO có mối quan hệ cùng chiều với rủi ro hoạt động của ngân hàng

\subsubsection{Sự đa dạng giới tính của thành viên $H Đ Q T$ và rủi ro của ngân hàng}

Đa dạng giới tính trong HĐQT đã và đang trở thành một chủ đề quan trọng trong hoạch định chính sách ở nhiều quốc gia, một số chính phủ đã thiết lập hạn nghạch cho các doanh nghiệp trong việc bổ sung các thành viên HĐQT là nữ giới. Nữ giới được đánh giá quản lý dân chủ hơn và có những kỹ năng nhằm tạo động lực cho nhân viên làm việc, minh bạch trong các hoạt động (Dutta \& Bose, 2006; Eagly \& Carli, 2003; Ferrero-Ferrero, Fernandez-Izquierdo, \& Muñoz-Torres, 2015; Hillman, Cannella, \& Harris, 2002; Letendre, 2004; Upadhyay \& Zeng, 2014; Zelechowski \& Bilimoria, 2004). Bên cạnh đó, do hiện tượng "rào chắn vô hình" (quan niệm về giới tính), phụ nữ thường phải cố gắng nhiều hơn để chứng minh năng lực của mình để đạt được vị trí trong HĐQT (Eagly \& Carli, 2003). Tại một số nghiên cứu thực nghiệm cho kết luận rằng, trong các công ty tài chính nhỏ, giám đốc nữ giúp công ty quản lý hiệu quả hơn (Chakrabarty \& Bass, 2014; GarcíaMeca et al., 2015; Strøm, D’Espallier, \& Mersland, 2014). Nghiên cứu của Owen và Temesvary (2018) lại cho thấy một mối quan hệ phi tuyến tính giữa sự đa dạng giới tính trong HĐQT và rủi ro trong hoạt động của ngân hàng khi chỉ ra sự tác động ngược chiều của sự đa dạng giới tính lên rủi ro trong hoạt động của ngân hàng khi số lượng nữ giới ở mức thấp và tác động cùng chiều khi số 
lượng nữ giới có sự gia tăng vượt quá ngưỡng 20\% số lượng thành viên trong HĐQT.

Tuy nhiên cũng có những nghiên cứu thực nghiệm lại chỉ ra rằng sự đa dạng giới tính trong HĐQT lại tác động cùng chiều với rủi ro của các ngân hàng. Nghiên cứu của Ararat, El-Helaly, và Shehata (2017) cho thấy rằng sự đa dạng giới tính thể hiện qua tỷ lệ thành viên nữ trong HĐQT có tác động cùng chiều với rủi ro trong hoạt động của doanh nghiệp tại Anh trên 34,798 công ty tại Anh giai đoạn từ 2005 - 2013 (kết quả tương tự với nghiên cứu của Talavera và các cộng sự, 2018 đối với các ngân hàng của Trung Quốc trong giai đoạn từ 2009 - 2013).

Dựa trên các nghiên cứu trước, kết quả chủ yếu tập trung vào việc sự đa dạng giới tính sẽ giúp cho hoạt động của doanh nghiệp tốt hơn, nên giả thuyết được xây dựng như sau:

$H_{3}$ : Đa dạng hóa giới tính trong $H Đ Q T$ có mối quan hệ cùng chiều với rủi ro hoạt động của ngân hàng

\subsubsection{Sụ đa dạng về quy mô $H Đ Q T$ và rủi ro của ngân hàng}

Quy mô của HĐQT được hiểu là tổng số lượng thành viên có trong HĐQT tính đến thời điểm nhất định, quy mô HĐQT lớn cho thấy hiệu quả giám sát tốt hơn qua việc chi phí đại diện giảm đi. Do đó, dẫn đến giảm rủi ro trong hoạt động và giá trị doanh nghiệp tăng (Singh \& Harianto, 1989). Ảnh hưởng của sự đa đạng về quy mô HĐQT đến rủi ro hoạt động của các ngân hàng được tìm thấy khá nhiều trong các nghiên cứu. Jensen (1993) cho rằng HĐQT của các công ty lớn thường ít hiệu quả hơn do các vấn đề hợp tác, kiểm soát và sự linh hoạt trong việc ra quyết định hoặc gây ra sự kiểm soát quá mức với Tổng giám đốc. Yermack (1996) bổ sung thêm lập luận cho rằng các công ty có quy mô HĐQT nhỏ có kết quả kinh doanh vượt trội hơn so với các công ty còn lại. Tuy nhiên những nhà nghiên cứu khác lại lập luận rằng các HĐQT có quy mô lớn có thể cải thiện hiệu quả hoạt động của doanh nghiệp bằng việc tạo điều kiện giám sát quản lý và đem lại nguồn lực dồi dào hơn để hỗ trợ và tư vấn cho Ban giám đốc (Coles, Daniel, \& Naveen, 2008; García-Meca et al., 2015). Tuy nhiên, trong nghiên cứu gần đây của Talavera và cộng sự (2018) thì quy mô của HĐQT không ảnh hưởng đến rủi ro trong hoạt động của ngân hàng. Các kết quả nghiên cứu thực nghiệm cho thấy không có một sự nhất quán về ảnh hưởng của sự đa dạng quy mô HĐQT lên rủi ro trong hoạt động của ngân hàng vì còn phụ thuộc vào rất nhiều các khía cạnh như môi trường kinh doanh của nước sở tại là đất nước phát triển hay đang phát triển, NHTM hay NHNN, các doanh nghiệp niêm yết trên sàn chứng khoán, ... tại thời điểm nghiên cứu. Các NHTM tại Việt Nam vẫn phải đang xử lý nợ xấu còn tồn đọng khá nhiều do đó rất cần có sự quản lý, giám sát chặt chẽ của một HĐQT có sự đa dạng về quy mô để vừa đảm bảo hoạt động hiệu quả vừa xử lý được các vấn đề còn tồn đọng đặc biệt là nợ xấu. Vì vậy, giả thuyết nghiên cứu liên quan đến sự đa dạng trong quy mô của HĐQT và rủi ro hoạt động của ngân hàng được xây dựng như sau:

\section{$H_{4}$ : Đa dạng hóa quy mô của HĐQT có mối quan hệ cùng chiều với rủi ro hoạt động của ngân hàng}

\subsubsection{Sụ đa dạng về thành viên độc lập trong $H Đ Q T$ và rủi ro của ngân hàng}

Theo quan điểm phụ thuộc nguồn lực thì sự hiện diện của các thành viên độc lập trong HĐQT có khuynh hướng làm giảm bớt xung đột lợi ích và hiệu quả hơn trong việc giảm vấn đề đại diện (Muttakin \& Ullah, 2012; Uddin, Mamum, Hoque, \& Uddin, 2013). Ngoài ra, còn có các nghiên cứu chỉ ra rằng nên gia tăng số lượng thành viên HĐQT độc lập để làm giảm bớt sức ảnh hưởng của chủ tịch HĐQT và đây cũng là nguyên nhân chính khiến nhiều nước gia tăng tỷ lệ thành viên HĐQT độc lập (García-Meca et al., 2015; Talavera et al., 2018), giả thuyết liên quan 
đến sự hiện diện của thành viên độc lập trong HĐQT như sau:

$H_{5}$ : Sư đa dạng về thành viên độc lập trong $H Đ Q T$ có mối quan hệ ngược chiều với rủi ro hoạt động của ngân hàng

\subsection{Mô hình nghiên cúu}

Dựa trên các nghiên cứu đi trước của Talavera và cộng sự (2018); Zhou và cộng sự (2019) tác giả đưa ra mô hình nghiên cứu về sự đa dạng của $\mathrm{HĐQT}$ và khoảng cách Chair-CEO với rủi ro ngân hàng có dạng sau:

$$
Y_{i t}=\alpha_{0}+\alpha Y_{i, t-1}+\sum_{i=1}^{4} \beta_{i} X_{i t}+\sum_{j=1}^{3} \gamma_{j} M_{i t}+\sum_{n=1}^{2} \lambda_{n} T_{i t}+\eta_{i}+\varepsilon_{i t}
$$

Trong đó:

- $Y_{i t}$ là rủi ro của của ngân hàng $i$ tại thời điểm $t$. Rủi ro của ngân hàng được đo lường bằng các chỉ số $Z_{-}$score $_{i}$; ROAA $\mathrm{A}_{\mathrm{it}}$;

- $\mathrm{X}_{\mathrm{it}}$ là véctơ các biến giải thích về khoảng cách giữa Chair-CEO gồm các biến: AbsAge chênh lệch tuổi của Chủ tịch HĐQT và Tổng giám đốc (số tuyệt đối), Age2 - chênh lệch tuổi bình phương của Chair-CEO, Gap20 - khoảng cách thế hệ giữa Chair-CEO (= 1 nếu tuổi của Chair và CEO chênh lệch ít nhất là 20 và ngược lại);

- $\mathrm{M}_{\mathrm{it}}$ là các biến đại diện cho sự đa dạng của HĐQT gồm Bgender - tỷ lệ số lượng thành viên nữ trong $\mathrm{HĐQT}$, Bsize - số lượng thành viên $\mathrm{HĐQT}$ và Binde - tỷ lệ số lượng thành viên độc lập trong HĐQT;

- $\mathrm{T}_{\text {it }}$ là các biến kiểm soát đại diện cho các yếu tố đặc trưng của ngân hàng gồm: Quy mô ngân hàng (Size), Tỷ lệ nợ (Loan_Ratio); thương mại;

- ๆi là ảnh hưởng cố định, đại diện cho sự khác biệt không quan sát được giữa các ngân hàng

- $\varepsilon_{\mathrm{it}}$ là thành phần sai số.

\subsection{Dĩ liệu và phưong pháp nghiên cúu}

Nghiên cứu sử dụng dữ liệu dạng bảng không cân bằng của 26 NHTM Việt Nam trong giai đoạn từ 2007 - 2017. Dữ liệu được thu thập từ báo cáo tài chính, báo cáo thường niên - là các báo cáo đã được kiểm toán và được công bố công khai với Ngân hàng Nhà nước và Ủy ban chứng khoán Nhà nước.

Các nghiên cứu về sự đa dạng của hội đồng quản trị và rủi ro của ngân hàng cần chú ý đến sự tương tác giữa các giá trị của biến rủi ro hoạt động theo thời gian đóng vai trò là biến độc lập trong mô hình nghiên cứu (Talavera et al., 2018). Do vậy, mô hình nghiên cứu về mối liên hệ sự đa dạng trong $\mathrm{HĐQT}$ và khoảng cách Chair-CEO với rủi ro của ngân hàng thường được xây dựng theo mô hình tự hồi quy (biến trễ của biến phụ thuộc rủi ro ngân hàng đóng vai trò là biến độc lập). Phương pháp ước lượng System GMM (SGMM) là phương pháp phù hợp nhất để khắc phục các khuyết tật gặp phải của mô hình nghiên cứu dựa theo đề xuât từ các nghiên cứu đi trước của Talavera và cộng sự (2018), Zhou và cộng sự (2019).

\section{Kết quả nghiên cứu và thảo luận}

\subsection{Thống kê mô tả}

Số liệu ở Bảng 2 cho thấy các biến đại diện cho rủi ro của ngân hàng là ROAA và Z_score 
có giá trị trung bình lần lượt là 0.012 và 1.85 , giá trị nhỏ nhất của hai biến này lần lượt là -0.060 với ROAA và -0.596 với $Z_{-}$score. Kết quả này cho thấy các $\mathrm{NHTM}$ có những thời điểm lợi nhuận âm và rủi ro phá sản cực kỳ cao. Điều này hoàn toàn có thể xảy ra bởi giai đoạn nghiên cứu từ 2007 - 2017 là giai đoạn có chứa đựng khủng hoảng kinh tế toàn cầu cũng như sự gia tăng nợ xấu của các NHTM lên cao kỷ lục.

Về khía cạnh khoảng cách giữa Chair-CEO thì biến AbsAge có giá trị trung bình là 8.639 với giá trị nhỏ nhất và lớn nhất lần lượt là 0 và 33. Số liệu này cho thấy có những NHTM có khoảng cách khá lớn về tuổi của Chair và $\mathrm{CEO}$, đây vừa có thể là thuận lợi nhưng cũng có thể là bất lợi trong cách điều hành và phát triển đặc biệt trong lĩnh vực ngân hàng.

\section{Bảng 1}

Kết quả thống kê mô tả các biến trong mô hình

\begin{tabular}{|l|c|c|c|c|c|}
\hline \multicolumn{1}{|c|}{ Biến } & Số quan sát & Giá trị trung bình & Độ lệch chuẩn & Giá trị nhỏ nhất & Giá trị lớn nhất \\
\hline Z_score & 235 & 1.85 & 0.642 & -0.596 & 4.25 \\
\hline ROAA & 263 & 0.012 & 0.01 & -0.06 & 0.061 \\
\hline AbsAge & 274 & 8.639 & 6.81 & 0 & 33 \\
\hline Gap20 & 286 & 0.063 & 0.243 & 0 & 1 \\
\hline Bgender & 274 & 0.171 & 0.159 & 0 & 0.63 \\
\hline Bsize & 274 & 7.182 & 1.88 & 3 & 14 \\
\hline Binde & 272 & 0.085 & 0.096 & 0 & 0.4 \\
\hline Loan_Ratio & 277 & 0.525 & 0.13 & 0.114 & 0.819 \\
\hline Size & 277 & 13.83 & 0.549 & 12.309 & 15.08 \\
\hline
\end{tabular}

Nguồn: Tính toán của các tác giả

\subsection{Ma trận hệ số tương quan}

Kết quả trong Bảng 2 cho thấy mối quan hệ giữa các biến $Z_{-}$score và ROAA đại diện cho rủi ro của các NHTM và các biến độc lập đều ở mức cho phép. Mức độ tương quan giữa các biến đều ở mức cho phép và nhỏ hơn 0.8 nên dấu hiệu đa cộng tuyến ít có khả năng xuất hiện.

\section{Bảng 2}

Ma trận hệ số tương quan

\begin{tabular}{|l|c|c|c|c|c|c|c|c|c|}
\hline & Z_score & ROAA & AbsAge & Gap20 & Bgender & Bsize & Binde & Loan_Ratio & Size \\
\hline Z_score & 1.000 & & & & & & & & \\
\hline ROAA & -0.073 & 1.000 & & & & & & & \\
\hline AbsAge & -0.218 & 0.076 & 1.000 & & & & & & \\
\hline Gap20 & -0.078 & -0.002 & 0.636 & 1.000 & & & & & \\
\hline Bgender & 0.066 & -0.177 & -0.093 & 0.072 & 1.000 & & & & \\
\hline Bsize & -0.030 & 0.167 & 0.108 & 0.116 & -0.019 & 1.000 & & & \\
\hline Binde & 0.167 & -0.278 & -0.092 & -0.038 & 0.134 & -0.153 & 1.000 & & \\
\hline Loan_Ratio & 0.043 & 0.041 & -0.171 & -0.148 & 0.003 & 0.056 & 0.005 & 1.000 & \\
\hline Size & 0.184 & -0.144 & -0.116 & 0.018 & 0.108 & 0.366 & 0.227 & 0.154 & 1.000 \\
\hline
\end{tabular}

Nguồn: Tính toán của các tác giả 


\subsection{Kết quả nghiên cúu}

Kết quả ước lượng mô hình nghiên cứu thực nghiệm về ảnh hưởng của sự đa dạng trong HĐQT và khoảng cách Chair-CEO với rủi ro của các NHTM bằng phương pháp SGMM được thể hiện ở Bảng 3 và 4 như sau:

\section{Bảng 3}

Kết quả ước lượng về khoảng cách Chair-CEO và sự đa dạng của HĐQT với Z_score

\begin{tabular}{|c|c|c|c|}
\hline & (1) & (2) & (3) \\
\hline L.Z_score & $\begin{array}{c}0.191 * * * \\
(4.95)\end{array}$ & $\begin{array}{c}0.175^{* * *} \\
\quad(5.27)\end{array}$ & $\begin{array}{c}0.257 * * * \\
(4.1)\end{array}$ \\
\hline AbsAge & $\begin{array}{l}0.018^{*} \\
(2.43)\end{array}$ & & $\begin{array}{c}0.108 * * \\
(2.7)\end{array}$ \\
\hline Gap20 & & $\begin{array}{l}-0.199 * \\
(-2.25)\end{array}$ & \\
\hline Age2 & & & $\begin{array}{l}-0.004 * \\
(-2.25)\end{array}$ \\
\hline Bgender & $\begin{array}{c}0.971 * * * \\
(5.07)\end{array}$ & $\begin{array}{c}1.075^{* * *} \\
(3.5)\end{array}$ & $\begin{array}{c}1.224 * * * \\
(4.37)\end{array}$ \\
\hline Bsize & $\begin{array}{c}-0.103 * * * \\
(-5.52)\end{array}$ & $\begin{array}{c}-0.224 * * * \\
(-5.53)\end{array}$ & $\begin{array}{c}-0.095 * * * \\
(-4.20)\end{array}$ \\
\hline Binde & $\begin{array}{c}-2.199 * * * \\
(-4.73)\end{array}$ & $\begin{array}{c}-2.350 * * * \\
(-4.35)\end{array}$ & $\begin{array}{c}-2.207 * * * \\
(-3.38)\end{array}$ \\
\hline Loan_Ratio & $\begin{array}{l}-0.763 * \\
(-2.09)\end{array}$ & $\begin{array}{c}-0.873 * * \\
(-3.23)\end{array}$ & $\begin{array}{l}-0.839 * \\
(-2.15)\end{array}$ \\
\hline Size & $\begin{array}{c}0.686 * * \\
(2.72)\end{array}$ & $\begin{array}{c}0.736 * * * \\
(3.79)\end{array}$ & $\begin{array}{c}0.669 * \\
(2.2)\end{array}$ \\
\hline Constant & $\begin{array}{l}-6.928 * \\
(-2.14)\end{array}$ & $\begin{array}{c}-6.445^{* *} \\
(-2.60)\end{array}$ & $\begin{array}{l}-7.174 \\
(-1.82)\end{array}$ \\
\hline $\begin{array}{l}\mathrm{AR}(1) \\
\text { [p-value] }\end{array}$ & $\begin{array}{l}-3.480 \\
0.001\end{array}$ & $\begin{array}{l}-3.32 \\
0.001\end{array}$ & $\begin{array}{l}-3.20 \\
0.001\end{array}$ \\
\hline $\begin{array}{l}\operatorname{AR}(2) \\
{[p \text {-value] }}\end{array}$ & $\begin{array}{c}1.25 \\
0.212\end{array}$ & $\begin{array}{c}1.11 \\
0.268\end{array}$ & $\begin{array}{c}1.36 \\
0.175\end{array}$ \\
\hline $\begin{array}{l}\text { Hansen } \\
\text { [p-value] }\end{array}$ & $\begin{array}{l}16.07 \\
0.653\end{array}$ & $\begin{array}{l}18.36 \\
0.499\end{array}$ & $\begin{array}{l}19.03 \\
0.327\end{array}$ \\
\hline $\mathrm{N}$ & 190 & 191 & 191 \\
\hline
\end{tabular}

Ghi chú: Hệ số hồi quy được thể hiện tương đương với các biến, trong ngoặc () là giá trị kiểm định t-stat của hệ số hồi quy. ***, **, * thể hiện mức ý nghĩa thống kê $1 \%, 5 \%$ và $10 \%$. L. thể hiện thông tin quá khứ

Nguồn: Kết quả phân tích từ Stata 


\section{Bảng 4}

Kết quả ước lượng về khoảng cách Chair-CEO và sự đa dạng của HĐQT với ROAA

\begin{tabular}{|c|c|c|c|}
\hline & (4) & (5) & (6) \\
\hline L.ROAA & $\begin{array}{c}0.187 * * * \\
(4.21)\end{array}$ & $\begin{array}{c}0.309 * * * \\
(7.84)\end{array}$ & $\begin{array}{c}0.298 * * * \\
(4.81)\end{array}$ \\
\hline AbsAge & $\begin{array}{c}0.000 * * \\
(-3.06)\end{array}$ & & $\begin{array}{c}0.000 * * \\
(3.05)\end{array}$ \\
\hline Gap20 & & $\begin{array}{c}-0.002 * \\
(-1.92)\end{array}$ & \\
\hline Age2 & & & $\begin{array}{c}-0.0002 * * \\
(-2.68)\end{array}$ \\
\hline Bgender & $\begin{array}{c}0.061 * * \\
(-2.72)\end{array}$ & $\begin{array}{c}-0.010 * * * \\
(-3.95)\end{array}$ & $\begin{array}{c}0.013^{*} \\
(2.1)\end{array}$ \\
\hline Bsize & $\begin{array}{c}0.002 * * * \\
(4.02)\end{array}$ & $\begin{array}{c}0.003 * * * \\
(4.93)\end{array}$ & $\begin{array}{c}0.002 * * * \\
(4.63)\end{array}$ \\
\hline Binde & $\begin{array}{c}-0.062 * * * \\
(-6.04)\end{array}$ & $\begin{array}{c}-0.011 * \\
(-2.04)\end{array}$ & $\begin{array}{c}-0.024 * * * \\
(-4.58) \\
\end{array}$ \\
\hline Loan_Ratio & $\begin{array}{c}0.031 * * * \\
(3.77)\end{array}$ & $\begin{array}{c}0.036 * * * \\
(7.16) \\
\end{array}$ & $\begin{array}{c}0.013 * * * \\
(3.42)\end{array}$ \\
\hline Size & $\begin{array}{c}-0.010 * * * \\
(-3.63) \\
\end{array}$ & $\begin{array}{c}-0.014 * * * \\
(-8.38) \\
\end{array}$ & $\begin{array}{c}-0.011 * * * \\
(-7.83) \\
\end{array}$ \\
\hline Constant & $\begin{array}{c}0.102 * * \\
(2.79)\end{array}$ & $\begin{array}{c}0.167 * * * \\
(8.46)\end{array}$ & $\begin{array}{c}0.138 * * * \\
(7.56)\end{array}$ \\
\hline $\begin{array}{l}\mathrm{AR}(1) \\
{[\mathrm{p} \text {-value] }}\end{array}$ & $\begin{array}{l}-1.75 \\
0.080\end{array}$ & $\begin{array}{l}-1.76 \\
0.078\end{array}$ & $\begin{array}{l}-1.73 \\
0.083\end{array}$ \\
\hline $\begin{array}{l}\operatorname{AR}(2) \\
\text { [p-value] }\end{array}$ & $\begin{array}{l}-0.54 \\
0.587\end{array}$ & $\begin{array}{c}0.39 \\
0.693\end{array}$ & $\begin{array}{c}0.68 \\
0.494\end{array}$ \\
\hline $\begin{array}{l}\text { Hansen } \\
\text { [p-value] }\end{array}$ & $\begin{array}{l}14.16 \\
0.896\end{array}$ & $\begin{array}{l}23.24 \\
0.506\end{array}$ & $\begin{array}{l}20.54 \\
0.765\end{array}$ \\
\hline $\mathrm{N}$ & 220 & 229 & 231 \\
\hline
\end{tabular}

Ghi chú: Hệ số hồi quy được thể hiện tương đương với các biến, trong ngoặc ( ) là giá trị kiểm định t-stat của hệ số hồi quy. ***,**,* thể hiện mức ý nghĩa thống kê $1 \%, 5 \%$ và $10 \%$. L. thể hiện thông tin quá khứ

Nguồn: Kết quả phân tích từ Stata

Qua kết quả ước lượng từ Bảng 3 và 4 cho thấy: với mô hình ước lượng sử dụng SGMM hệ số ước lượng của Hansen ( 2 bước) có giá trị p-value lớn hơn $5 \%$ đồng nghĩa với số lượng biến công cụ đưa vào mô hình phù hợp và đầy đủ. Bên cạnh đó, giá trị $p$-value của các kiểm định tự tương quan bậc 2 - $\mathrm{AR}(2)$ - đều có giá trị lớn hơn 10\% xác nhận việc kết quả hợp lệ. Các hệ số lượng ổn định cho các mô hình (1), (2) và (3), cũng như (4), (5) và (6) cho các kết quả ổn định. Nên Phương pháp ước lượng SGMM phù hợp và bảo đảm tính ổn định của các hệ số ước lượng đối với dữ liệu và mô hình đề xuất. 


\subsection{Thảo luận kết quả nghiên cúu}

\subsubsection{Khoảng cách Chair-CEO}

Sự khác biệt về nhận thức giữa Chair và $\mathrm{CEO}$ xảy ra khi họ có sự khác biệt về tuổi và ngược lại. Khi Chair và $\mathrm{CEO}$ trong cùng thế hệ họ dễ dàng cùng nhìn nhận giống nhau về các mục tiêu phát triển cũng như các phương hướng hoạt động của ngân hàng. Sự đồng điệu này có thể làm gia tăng lợi nhuận của ngân hàng nhưng cũng có thể làm cho ngân hàng gặp nhiều rủi ro khi mà mọi quyết định của Chair và $\mathrm{CEO}$ đều có sự thống nhất cao. Chính bởi lý do này mà trong nghiên cứu này tác giả hy vọng sẽ chỉ rõ được mối quan hệ giữa Chair và $C E O$. Để đo lường khoảng cách giữa Chair-CEO một cách đầy đủ nhất có thể nghiên cứu sử dụng bốn biến độc lập gồm AbsAge đo lường sự khác biệt về tuổi, Gap20 đo lường khoảng cách thế hệ và cuối cùng là Age2 để đo lường mối quan hệ phi tuyến tính về tuổi của Chair-CEO. Kết quả nghiên cứu thực nghiệm trong Bảng 3 và 4 về ba biến đại diện cho khoảng cách thế Chair-CEO cho thấy cụ thể như sau:

Vî̀ biến độc lập AbsAge kết quả nghiên cứu cho thấy nó có mối quan hệ cùng chiều với Z_score và hoàn toàn phù hợp với giả thuyết nêu ra. Khi sự khác biệt về tuổi của Chair-CEO tăng đồng nghĩa nhận thức của hai nhân vật quan trọng nhất này sẽ có sự khác biệt rõ rệt. Sự khác biệt này đến từ nhiều khía cạnh trong đó có nhận thức, kinh nghiệm, hiểu biết cũng như những thất bại và thành công. Điều này vô tình làm cho mọi quyết định trong các hoạt động của ngân hàng liên quan đến sự phát triển của ngân hàng được xem xét rất kỹ lưỡng dựa trên cả hai khía cạnh cơ hội lẫn rủi ro. Sự khác biệt về tuổi càng lớn đồng nghĩa một trong hai nhân vật quan trọng nhất của ngân hàng là Chair và $\mathrm{CEO}$ sẽ nhìn nhận các phương hướng hoạt động của ngân hàng trên cả hai khía cạnh kinh nghiệm hiện tại lẫn quá khứ. Tại các NHTM ở Việt Nam thường sự chênh lệch về tuổi theo chiều hướng Chair lớn hơn $\mathrm{CEO}$ nên sẽ làm gia tăng khả năng giám sát của HĐQT trong mọi quyết định của $\mathrm{CEO}$ và ban giám đốc. Trong nghiên cứu này để làm rõ sự khác biệt về tuổi càng lớn sẽ càng làm cho rủi ro của các ngân hàng giảm tác giả đã thực hiện lấy trị tuyệt đối sự khác biệt về tuổi của Chair-CEO với biến AbsAge. Kết quả này củng cố cho cho các nghiên cứu của Phan, Anwar, Alexabder, và Phan (2019), Talavera và cộng sự (2018), Zhou và cộng sự (2019).

Mặt khác khi rủi ro của các ngân hàng giảm do các hoạt động được kiểm soát chặt bởi sự khác biệt về khoảng cách giữa Chair-CEO kéo theo lợi nhuận của các ngân hàng có sự gia tăng. Kết quả nghiên cứu thực nghiệm cho thấy có mối quan hệ cùng chiều giữa ROAA và AbsAge phù hợp với kỳ vọng của nghiên cứu là khi rủi ro được kiểm soát chặt thì lợi nhuận của các ngân hàng sẽ gia tăng. Kết quả này khẳng định rằng khoảng cách giữa Chair-CEO không chỉ giúp các ngân hàng kiểm soát cũng như giám sát tốt nguồn vốn mà còn đảm bảo mọi hoạt động của ngân hàng được ổn định. Đây chính là điều kiện để đảm bảo cho một kết quả kinh doanh thuận lợi và thực tế đã chứng minh các ngân hàng có đội ngũ HĐQT đa dạng đặc biệt về tuổi sẽ đảm bảo vai trò giám sát cũng như tư vấn cho Ban giám đốc tốt hơn là một đội ngũ HĐQT ít có sự đa dạng cũng như khoảng cách giữa Chair-CEO nhỏ. Kinh nghiệm của Chair là điều không cần bàn cãi tuy nhiên kinh nghiệm đó có hay không góp phần làm cho vai trò giám sát cũng như tư vấn cho Ban giám đốc hiệu quả lại là một câu hỏi cần có câu trả lời. Với kết quả thực nghiệm đạt được nghiên cứu có thể khẳng định khi khoảng cách giữa Chair-CEO lớn sẽ tăng khả năng giám sát, tư vấn làm giảm rủi ro trong hoạt động và gia tăng lợi nhuận của các ngân hàng. Kết quả này phù hợp với Talavera và cộng sự (2018), Zhou và cộng sự (2019).

Về biến độc lập Gap20, Age2 kết quả nghiên cứu thực nghiệm cho thấy nó tác động ngược chiều với hệ số $Z$ score, trái với giả thuyết được nêu. Kết luận này được hiểu là khi khoảng cách tuổi giữa Chair và $\mathrm{CEO}$ quá lớn (ít nhất 20 tuổi) thì sự xung đột nhận thức không còn đơn thuần mang tính chất bổ sung các khuyết điểm của nhau mà dẫn đến sự mâu thuẫn trong mọi hoạt động 
của ngân hàng. Sự chênh lệch tuổi tác quá lớn giữa Chair và $\mathrm{CEO}$ làm cho những kinh nghiệm, nhận thức mà Chair có được quá khác biệt so với $\mathrm{CEO}$ và điều này không giúp ích được nhiều cho các chiến lược phát triển của ngân hàng. Mặt khác khoảng cách này làm cho hệ tư tưởng của Chair và $\mathrm{CEO}$ quá khác nhau, một bên luôn cẩn trọng trong mọi hoạt động và giám sát rất chặt trong khi bên còn lại thì luôn mong muốn gia tăng hiệu quả hoạt động của ngân hàng thông qua nhiều kế hoạch khác nhau. Kết cục tất yếu đó là $\mathrm{CEO}$ sẽ tìm cách để mọi kế hoạch hoạt động của Ban giám đốc được Chair và HĐQT thông qua vô tình sẽ đẩy $\mathrm{CEO}$ lao vào các hoạt động gặp nhiều rủi ro bởi không còn nhận được sự tư vấn cũng như giám sát như kỳ vọng. Để làm rõ hơn điều này nghiên cứu đã thêm vào biến độc lập Age2 để kiểm chứng có hay không tồn tại mối quan hệ phi tuyến tính giữa khoảng cách Chair-CEO cũng như khẳng định kết quả nghiên cứu với biến Gap20 là đúng. Kết quả thực nghiệm thu được phản ánh khoảng cách tuổi giữa Chair và $\mathrm{CEO}$ gia tăng thì rủi ro của các ngân hàng sẽ giảm nhưng khi sự khác biệt về tuổi giữa Chair và $\mathrm{CEO}$ quá lớn thể hiện qua hệ số hồi quy đứng trước Age2 mang dấu âm thì sự khác biệt về tuổi này lại có tác dụng ngược chiều với rủi ro của các ngân hàng. Mối quan hệ phi tuyến tính giữa khoảng cách ChairCEO qua biến Age2 và rủi ro tồn tại đã khẳng định kết quả về dấu của biến Gap20 trong mô hình nghiên cứu là chính xác.

Trên khía cạnh lợi nhuận của ngân hàng là ROAA cũng cho thấy một kết quả tương tự. Khoảng cách thế hệ giữa Chair-CEO qua biến Gap20 cho thấy khi Chair-CEO có tuổi quá cách biệt nhau (ít nhất 20 tuổi) sẽ làm cho rủi ro ngân hàng tăng lên đồng nghĩa lợi nhuận của ngân hàng gặp nhiều khó khăn.

Để có thể nhìn nhận một cách đầy đủ nhất về khoảng cách thế hệ Chair-CEO thật sự khi nào thì tốt khi nào thì xấu nghiên cứu có tìm hiểu thêm có hay không tồn tại mối quan hệ phi tuyến tính giữa Chair-CEO dựa trên gợi ý của nghiên cứu Zhou và cộng sự (2019). Kết quả nghiên cứu thực nghiệm chỉ ra rằng có sự tồn tại về một mối quan hệ phi tuyến tính giữa tuổi của Chair và CEO với ROAA thể hiện qua sự chênh lệch về tuổi của Chair và $\mathrm{CEO}$ ở một chừng mực nhất định (ít hơn 20 tuổi) sẽ giúp cho lợi nhuận của ngân hàng gia tăng (AbsAge có quan hệ cùng chiều với ROAA) nhưng nếu sự khác biệt này quá lớn thì sẽ làm giảm lợi nhuận của các ngân hàng (hệ số hồi quy trước Age2 âm). Kết quả này góp phần khẳng định nhận định khoảng cách thế hệ giữa Chair và $C E O$ qua biến Gap20 là đáng tin cậy (tương tự với kết quả của Waelchli \& Zeller, 2013).

\subsection{2. Đa dạng trong $H Đ Q T$}

Trong mọi hoạt động của ngân hàng vai trò của HĐQT luôn là rất quan trọng bởi đây là những thành viên đại diện cho quyền lợi của tất cả các cổ đông trong ngân hàng. Mặt khác với một lĩnh vực khá nhạy cảm như ngân hàng thì vai trò của HĐQT lại càng quan trọng bởi để ngân hàng đối mặt với rủi ro đồng nghĩa với việc nền kinh tế sẽ gặp nhiều khó khăn. Trong nghiên cứu này sự đa dạng của HĐQT được thể hiện qua các khía cạnh đó là sự đa dạng về quy mô (Bsize), đa dạng về thành viên độc lập (Binde) và đa dạng về giới tính (Bgender). Kết quả nghiên cứu thực nghiệm trong Bảng 3 và 4 cho thấy các nhận định sau:

Đối với Bgender kết quả nghiên cứu thực nghiệm cho thấy Bgender có mối quan hệ cùng chiều với $Z$ score phù hợp với giả thuyết được nêu trong chương 3 . Kết quả này ủng hộ lập luận cho rằng số lượng nữ thành viên trong HĐQT mang đến các kỹ năng tư vấn và các đặc điểm cá nhân cho HĐQT góp phần cải thiện hiệu quả giám sát hoạt động của Ban giám đốc từ đó giúp hạn chế rủi ro trong hoạt động của các ngân hàng. Bên cạnh đó tầm quan trọng của thành viên nữ trong HĐQT thể hiện rõ ở ba lý do chính gồm (1) thành viên nữ trong HĐQT hiểu biết đặc điểm của thị trường cụ thể tốt hơn nam giới, do đó sẽ mang lại nhiều chất lượng hơn khi ra quyết định cho HĐQT, (2) khi có sự hiện diện của thành viên nữ trong HĐQT sẽ xây dựng được hình ảnh mang tính cộng đồng tốt hơn cho ngân hàng do đó hoạt động của ngân hàng hiệu quả hơn, (3) khi nữ 
giới được bổ nhiệm vào thành viên $\mathrm{HĐQT}$ sẽ giúp cho HĐQT gia tăng tri thức, sự hiểu biết đồng thời các nữ quản lý cấp cao có thể ảnh hưởng tích cực đến sự phát triển nghề nghiệp của các đồng nghiệp nữ dưới quyền. Kết quả về ảnh hưởng tích cực của Bgender đến hiệu quả hoạt động của ngân hàng cũng được sự đồng thuận khi ROAA cũng có mối quan hệ cùng chiều với Bgender (đồng quan điểm với García-Meca et al., 2015; Duong \& Diep, 2017).

Về biến độc lập Bsize kết quả nghiên cứu cho thấy biến này có mối quan hệ ngược chiều với Z_score, trái với giả thuyết được nêu. Quy mô $\mathrm{HĐQT}$ lớn sẽ có những thuận lợi cho ngân hàng trong việc nâng cao chức năng của ban quản trị như việc hỗ trợ tư vấn, giảm chuyên quyền của các nhà quản lý, tận dụng được nhiều mối quan hệ của các thành viên trong HĐQT. Tuy nhiên sự gia tăng về quy mô HĐQT nên được kiểm soát ở một mức độ nào đó bởi khi khi có sự gia tăng lớn về quy mô $\mathrm{HĐQT}$ sẽ xuất hiện những tính phi hiệu quả làm ảnh hưởng bất lợi đến những lợi nhuận ban đầu. Khả năng điều phối công việc và trao đổi thông tin là hai vấn đề mà quy mô HĐQT lớn sẽ phải đối mặt đồng thời việc mở rộng quy mô HĐQT sẽ làm chi phí đại diện tăng, làm cho việc giám sát ban giám đốc bị phân tán gây rủi ro trong hoạt động của các ngân hàng (kết quả tương tự với Talavera et al., 2018).

Lợi nhuận luôn đi kèm với rủi ro đây là điều hoàn toàn đã xảy ra khi sự kiểm soát của HĐQT không phát huy được hiệu quả đặc biệt trong lĩnh vực ngân hàng. Thực tế cho thấy các ngân hàng khi lao vào các lĩnh vực như bất động sản, chứng khoán, là những lĩnh vực có rất nhiều rủi ro thường kèm theo là các khoản lợi nhuận rất lớn. Kết quả nghiên cứu thực nghiệm cho thấy giữa ROAA và Bsize có mối quan hệ cùng chiều. Khi quy mô HĐQT tăng thì đồng nghĩa việc kiểm soát mọi hoạt động của Ban giám đốc sẽ bị phân tán rất nhiều dẫn đến các hoạt động của Ban giám đốc ít bị ảnh hưởng bởi các HĐQT có quy mô lớn (Bushman \& Smith, 2001). Kết quả nghiên cứu này của tác giả phù hợp các nghiên cứu đi trước của Vallascas, Mollah, và Keasey (2017), García-Meca và cộng sự (2015), Talavera và cộng sự (2018).

Về biến độc lập Binde kết quả nghiên cứu cho thấy có một mối quan hệ ngược chiều với Z_score, phù hợp với giả thuyết được nêu. Khi số lượng thành viên độc lập trong HĐQT tăng thường kéo theo xung đột về các quyết định của $\mathrm{HĐQT}$ do các thành viên độc lập gia tăng việc kiểm soát các quyết định của $\mathrm{HĐQT}$, họ có thể sẽ thiếu hiểu biết đầy đủ về đặc điểm cụ thể của ngân hàng nên có thể sẽ đưa các quyết định không tối ưu làm cho hoạt động của ngân hàng gặp rủi ro. Điều này thực tế cũng cho thấy ở các NHTM tại Việt Nam số lượng thành viên độc lập thường rất ít cho thấy các NHTM rất sợ các quyết định mang tính chất chủ quan ảnh hưởng đến hiệu quả hoạt động của các ngân hàng. Mặt khác việc gia tăng số lượng thành viên HĐQT độc lập là những người không tham gia hoạt động trực tiếp trong ngân hàng cũng gây ra rất nhiều khó khăn như các thành viên độc lập có thể có xu hướng củng cố vị trí hoặc có xu hướng muốn làm hài lòng các thành viên HĐQT khác và ban điều hành, qua đó các thành viên độc lập có thể chỉ quan tâm tới quyền lợi cá nhân, thay vì bảo vệ quyền lợi các cổ đông. Kết quả về mối quan hệ ngược chiều này cũng nhận được sự đồng thuận khi phân tích mối quan hệ giữa ROAA và Binde. Do vai trò quan trọng của các thành viên độc lập mà các ngân hàng sẵn sàng trả một khoản thù lao lớn để họ thực hiện nhiệm vụ giám sát hoạt động của bộ máy quản lý, điều hành. Điều này cũng có tính hai mặt bởi thực tế có thể các thành viên độc lập này sẽ không quan tâm nhiều tới việc thực thi nhiệm vụ mà chỉ chú ý củng cố vị trí nhằm được hưởng thù lao hậu hĩnh nói trên. Kết quả nghiên cứu tương đồng với Talavera và cộng sự (2018); Uddin và cộng sự (2013).

\section{Kết luận và khuyến nghị}

\subsection{Kết luận}

Kết quả nghiên cứu cho thấy khoảng cách Chair-CEO được thể hiện qua các biến gồm 
AbsAge, Gap20 và Age2 đều có ảnh hưởng đến rủi ro trong hoạt động của các NHTM thể hiện qua hai khía cạnh là $Z_{-}$score và ROAA cụ thể như sau:

Khoảng cách Chair-CEO trên khía cạnh chênh lệch tuổi qua biến AbsAge có tác động làm giảm thiểu rủi ro trong hoạt động của các NHTM đồng thời góp phần gia tăng hiệu quả hoạt động của các NHTM. Kết quả nghiên cứu cho thấy khi giữa Chair và $C E O$ có khoảng cách về tuổi tác thì mọi quyết định sẽ được xem xét kỹ lường góp phần đảm bảo nó được giám sát tốt nhất giúp hạn chế rủi ro cũng như nâng cao hiệu quả hoạt động.

Khoảng cách Chair-CEO thể hiện qua hai biến gồm Gap20 và Age2 có tác động gia tăng rủi ro của các NHTM. Kết quả nghiên cứu cho thấy khi giữa Chair và CEO có sự khác biệt về tuổi ở mức độ khá lớn thì những kinh nghiệm của Chair sẽ không còn phù hợp nữa và điều này làm cho việc giám sát sẽ không phát huy hiệu quả dẫn đến các ngân hàng sẽ gặp nhiều rủi ro trong hoạt động của mình. Đồng thời kết quả này hàm ý có tồn tại mối quan hệ phi tuyến tính giữa khoảng cách thế hệ Chair-CEO với rủi ro của các ngân hàng.

Sự đa dạng của HĐQT trong nghiên cứu thể hiện qua các biến như Binde, Bsize và Bgender đều có ảnh hưởng đến rủi ro trong hoạt động của các NHTM qua các biến $Z$ _score và ROAA. Trong đó Binde cho thấy tỷ lệ số lượng thành viên HĐQT độc lập có ảnh hưởng ngược chiều với $Z$ _score và $R O A A$ trong khi tỷ lệ thành viên thành viên nữ (Bgender) lại cho thấy ảnh hưởng tích cực đến việc giảm thiểu rủi ro cũng như nâng cao hiệu quả hoạt động của các NHMT. Cuối cùng là biến Bsize có ảnh hưởng ngược chiều với Z_score và thuận chiều với ROAA.

\subsection{Khuyến nghị}

Chair và $C E O$ là hai nhân vật quan trọng nhất trong HĐQT và Ban giám đốc. Các quyết định của họ đều ảnh hưởng rất lớn đến hiệu quả hoạt động của ngân hàng, một lĩnh vực được xem như là trái tim của nền kinh tế. Các ngân hàng cần chọn lựa đội ngũ trong HĐQT và Ban giám đốc có sự khác biệt về tuổi tác, sự đa dạng tuổi tác này sẽ kéo theo việc nhận thức, kinh nghiệm, quan điểm, ... khác nhau tạo điều kiện thuận lợi cho việc đưa ra các quyết định cũng như việc giám sát được hiệu quả. Trong đó đặc biệt là Chair và $\mathrm{CEO}$ nên có sự khác biệt về tuổi để đảm bảo mọi kế hoạch của $C E O$ và Ban giám đốc đều được giám sát cũng như kiểm soát chặt chẽ. $C E O$ và Ban giám đốc nên là những người trẻ năng động, nhiệt huyết và có trình độ chuyên môn cao trong khi Chair và $\mathrm{HĐQT}$ nên là những người có độ tuổi lớn hơn để đảm bảo mọi quyết định đều dựa trên quyền lợi của cổ đông cũng như hạn chế thấp nhất rủi ro trong hoạt động.

HĐQT luôn đóng một vai trò quan trọng trong sự phát triển của các công ty đặc biệt ở lĩnh vực ngân hàng thì vai trò của HĐQT còn quan trọng hơn rất nhiều. Sự đa dạng của HĐQT nên được xem trong đặc biệt ở các khía cạnh về số lượng thành viên nữ trong HĐQT, cần có sự gia tăng bởi đây là những thành viên có sự suy nghĩ khác biệt theo nhiều khía cạnh như cẩn thận, chắc chắn và luôn có sự tin cậy nhất định trong mọi quyết định của mình, thực tế cũng cho thấy các ngân hàng có số lượng nữ thành viên trong HĐQT cao thường hoạt động hiệu quả, ít gặp phải rủi ro hơn. Quy mô HĐQT của các ngân hàng cần có sự thay đổi cho phù hợp với hoạt động của ngân hàng đồng nghĩa các ngân hàng có thị phần nhỏ, ít lĩnh vực hoạt động nên có quy mô HĐQT nhỏ để đảm bảo mọi quyết định đều được giám sát và xử lý một cách nhanh chóng nâng cao cơ hội cạnh tranh với các ngân hàng khác. Trên khía cạnh thành viên độc lập của HĐQT thì không nên có sự gia tăng quá nhiều chỉ khi các ngân hàng có ý định mở rộng hoạt động, kêu gọi vốn đầu tư từ các tổ chức đặc biệt nước ngoài thì mới cần gia tăng sự mở rộng về các thành viên độc lập. 


\section{Tài liệu tham khảo}

Adams, R. B., \& Ferreira, D. (2007). A theory of friendly boards. The Journal of Finance, 62(1), 217-250.

Alchian, A. A., \& Demsetz, H. (1972). Production, information costs, and economic organization. The American Economic Review, 62(5), 777-795.

Ararat, M., El-Helaly, M., \& Shehata, N. F. (2017). Boards' gender diversity and firm performance before and after the Egyptian revolution. Retrieved May 10, 2020, from https://papers.ssrn.com/sol3/papers.cfm?abstract_id=3063867

Beltratti, A., \& Stulz, R. M. (2012). The credit crisis around the globe: Why did some banks perform better? Journal of Financial Economics, 105(1), 1-17.

Berger, A. N., Klapper, L. F., \& Turk-Ariss, R. (2017). Bank competition and financial stability. In J. A. Bikker \& L. Spierdijk (Eds.), Handbook of competition in banking and finance (pp. 185-204). Cheltenham, UK: Edward Elgar Publishing.

Bushman, R. M., \& Smith, A. J. (2001). Financial accounting information and corporate governance. Journal of Accounting and Economics, 32(1/3), 237-333.

Chakrabarty, S., \& Bass, A. E. (2014). Corporate governance in microfinance institutions: Board composition and the ability to face institutional voids. Corporate Governance: An International Review, 22(5), 367-386.

Coles, J. L., Daniel, N. D., \& Naveen, L. (2008). Boards: Does one size fit all? Journal of Financial Economics, 87(2), 329-356.

Duong, B. V., \& Diep, N. H. (2017). Đặc điểm hội đồng quản trị và hành vi quản trị lợi nhuận của các công ty niêm yết trên thị trường chứng khoán Việt Nam [Board characteristics and profit management behavior of companies listed on Vietnam stock market]. Tap chí Khoa hoc Đại học Mở Thành phố Hồ Chí Minh, 12(3), 113-126.

Dutta, P., \& Bose, S. (2006). Gender diversity in the boardroom and financial performance of commercial banks: Evidence from Bangladesh. The Cost and Management, 34(6), 70-74.

Eagly, A. H., \& Carli, L. L. (2003). The female leadership advantage: An evaluation of the evidence. The Leadership Quarterly, 14(6), 807-834.

Faleye, O., \& Krishnan, K. (2017). Risky lending: Does bank corporate governance matter? Journal of Banking and Finance, 83, 57-69.

Fama, E. F., \& Jensen, M. C. (1983). Separation of ownership and control. The Journal of Law and Economics, 26(2), 301-325.

Ferrero-Ferrero, I., Fernandez-Izquierdo, M. A., \& Muñoz-Torres, M. J. (2015). Integrating sustainability into corporate governance: An empirical study on board diversity. Corporate Social Responsibility and Environmental Management, 22, 193-207.

Forbes, D. P., \& Milliken, F. J. (1999). Cognition and corporate governance: Understanding boards of directors as strategic decision-making groups. Academy of Management Review, 24(3), 489-505.

Fracassi, C., \& Tate, G. (2012). External networking and internal firm governance. The Journal of Finance, 67(1), 153-194. 
García-Meca, E., García-Sánchez, I. M., \& Martínez-Ferrero, J. (2015). Board diversity and its effects on bank performance: An international analysis. Journal of Banking and Finance, 53(1), 202-214.

Goergen, M., Limbach, P., \& Scholz, M. (2015). Mind the gap: The age dissimilarity between the chair and the CEO. Journal of Corporate Finance, 35, 136-158.

Harrison, D. A., Price, K. H., \& Bell, M. P. (1998). Beyond relational demography: Time and the effects of surface-and deep-level diversity on work group cohesion. Academy of Management Journal, 41(1), 96-107.

Hillman, A. J., Cannella, A. A., Jr., \& Harris, I. C. (2002). Women and racial minorities in the boardroom: How do directors differ? Journal of Management, 28(6), 747-763.

Jensen, M. C. (1993). The modern industrial revolution, exit, and the failure of internal control systems. The Journal of Finance, 48(3), 831-880.

Letendre, L. (2004). The dynamics of the boardroom. Academy of Management Perspectives, 18(1), 101-104.

Liang, Q., Xu, P., \& Jiraporn, P. (2013). Board characteristics and Chinese bank performance. Journal of Banking and Finance, 37(8), 2953-2968.

McPherson, M., Smith-Lovin, L., \& Cook, J. M. (2001). Birds of a feather: Homophily in social networks. Annual Review of Sociology, 27(1), 415-444.

Minton, B. A., Taillard, J. P., \& Williamson, R. (2014). Financial expertise of the board, risk taking, and performance: Evidence from bank holding companies. Journal of Financial and Quantitative Analysis, 49(2), 351-380.

Muller-Kahle, M. I., \& Lewellyn, K. B. (2011). Did board configuration matter? The case of US subprime lenders. Corporate Governance: An International Review, 19(5), 405-417.

Muttakin, M. B., \& Ullah, S. (2012). Corporate governance and bank performance: Evidence from Bangladesh. Corporate Board: Role, Duties and Composition, 8(1), 62-68.

Owen, A. L., \& Temesvary, J. (2018). The performance effects of gender diversity on bank boards. Journal of Banking and Finance, 90, 50-63. doi:10.1016/j.jbankfin.2018.02.015

Peni, E., \& Vähämaa, S. (2012). Did good corporate governance improve bank performance during the financial crisis? Journal of Financial Services Research, 41(1/2), 19-35.

Phan, H. T., Anwar, S., Alexander, W. R., \& Phan, H. T. M. (2019). Competition, efficiency and stability: An empirical study of East Asian commercial. North American Journal of Economics and Finance, 50, Article 100990. doi:10.1016/j.najef.2019.100990

Serfling, M. A. (2014). CEO age and the riskiness of corporate policies. Journal of Corporate Finance, 25, 251-273. doi:10.1016/j.jcorpfin.2013.12.013

Singh, H., \& Harianto, F. (1989). Management-board relationships, takeover risk, and the adoption of golden parachutes. Academy of Management Journal, 32(1), 7-24.

Srivastav, A., \& Hagendorff, J. (2016). Corporate governance and bank risk-taking. Corporate Governance: An International Review, 24(3), 334-345.

Strøm, R. Ø., D’Espallier, B., \& Mersland, R. (2014). Female leadership, performance, and governance in microfinance institutions. Journal of Banking and Finance, 42, 60-75. doi:10.1016/j.jbankfin.2014.01.014 
Talavera, O., Yin, S., \& Zhang, M. (2018). Age diversity, directors' personal values, and bank performance. International Review of Financial Analysis, 55, 60-79.

Uddin, M. R., Mamun, A. M. A., Hoque, N., \& Uddin, M. S. (2013). Work-life balance: A study on female teachers of private education institutions of Bangladesh. Work, 5(13), 10-17.

Upadhyay, A., \& Zeng, H. (2014). Gender and ethnic diversity on boards and corporate information environment. Journal of Business Research, 67(11), 2456-2463.

Vallascas, F., Mollah, S., \& Keasey, K. (2017). Does the impact of board independence on large bank risks change after the global financial crisis? Journal of Corporate Finance, 44, 149-166.

Van der Walt, N., Ingley, C., Shergill, G. S., \& Townsend, A. (2006). Board configuration: Are diverse boards better boards? Corporate Governance: The International Journal of Business in Society, 6(2), 129-147.

Waelchli, U., \& Zeller, J. (2013). Old captains at the helm: Chairman age and firm performance. Journal of Banking and Finance, 37, 1612-1628.

Westphal, J. D., \& Zajac, E. J. (1995). Who shall govern? CEO/board power, demographic similarity, and new director selection. Administrative Science Quarterly, 40(1), 60-83.

Yermack, D. (1996). Higher market caluation of companies with a small board of directors. Journal of Financial Economics, 40(2), 185-211.

Zelechowski, D. D., \& Bilimoria, D. (2004). Characteristics of women and men corporate inside directors in the US. Corporate Governance: An International Review, 12(3), 337-342.

Zhou, Y., Kara, A., \& Molyneux, P. (2019). Chair-CEO generation gap and bank risk-taking. The British Accounting Review, 51(4), 352-372. 